\title{
Students leading the way A micro-adaptation of UCLA's WI+RE model to create information literacy tutorials
}

$\mathbf{T}$ he COVID-19 pandemic necessitated that libraries quickly migrate information literacy instruction to an entirely online format. In traditional classroom instruction, librarians have arguably greater flexibility in terms of how we can actively engage students in brainstorming keywords, developing their topics, and constructing Boolean searches. All of the sudden, we were all scrambling to put together lesson plans for the online environment, and library tutorials were in great demand. Coincidentally, at the University of Illinois-Chicago (UIC) we had already embarked upon a student-centered tutorial creation project about a month before the pandemic's onset, which allowed us to bolster our online instructional presence through the generation of student-centered learning objects.

\section{Inspiration}

The inspiration for this project came from an exciting presentation that two of us attended at the LOEX annual conference in 2019. ${ }^{1}$ During this presentation, Renee Romero, Doug Worsham, and Annie Pho described the UCLA WI+RE (Writing Instruction and Research) ${ }^{2}$ program, and, in particular, their student-led media creation, outlining their guiding values, design principles, and pedagogy. This presentation resonated with us for a variety of reasons, but in particular because we shared their values for culturally sustaining pedagogy and studentcentered, student-led teaching. We had created some instructional video tutorials in the past in a somewhat ad hoc manner, and began envisioning a new project as Romero, Worsham, and Pho led the attendees through an empathy mapping exercise. Empathy mapping is one method the presenters used with their students to brainstorm media projects. The empathy map, as well as other design documents, are provided in a toolkit, which they've made freely available.

As much as we would have loved to replicate UCLA's program at the UIC Library, we realized that we had to scale down the project to fit our needs. We didn't have a dedicated librarian or instructional designer who could oversee the project, and although there were three of us involved, we didn't have the time or resources to invest in something large scale. Nonetheless, we modeled our project after UCLA's program, using their design toolkit and retaining the principles of a student-led, student-centered project intact.

In fall 2019, we applied for a modest innovation "seedling grant" offered within our library at UIC to experiment with this model. This grant supports programs over a one-year period aimed at benefiting the library or library patrons. This program allows librarians to test ideas and pilot projects not included in the annual budget. Grant funds can be spent on technology, travel, or staff. Our team submitted a proposal in fall 2019, and following review, we were awarded $\$ 2,000$.

The benefits of this project were multifaceted, both to the library and to the students we hoped to recruit. While we appreciated the value of developing creative online learning objects to deliver or enhance library instruction, we also knew from experience that this process can be time-consuming and can necessitate hiring content experts, such

Catherine Lantz is reference and instruction librarian, associate professor, email: clantz@uic.edu, Glenda Insua is reference and instruction librarian, associate professor, email: ginsua1@uic.edu, and Annie Armstrong is reference librarian and coordinator of teaching and learning services, associate professor, email: annie@uic. edu at the University of Illinois-Chicago

(c) 2021 Catherine Lantz, Glenda Insua, and Annie Armstrong 
as animators or instructional designers, to realize and elevate a creative vision. ${ }^{3}$ While we could have designed another tutorial from the librarian's point of view and used grant money to hire an animator to realize "our vision," we sought to flip the narrative, and see what might happen if we enlisted students to immerse themselves in learning about tutorials, with the goal of generating a learning object in which they could communicate their own learning about information literacy and tutorials to an audience of their peers.

The resulting product would be enriched by the use of their own language, creative vision, and unique skill sets.

In a sense, we wanted to create an information literacy incubation experience, capitalizing on the idea of studentcentered learning and team-based learning as they did at UCLA. In designing the project, we kept the subject-matter

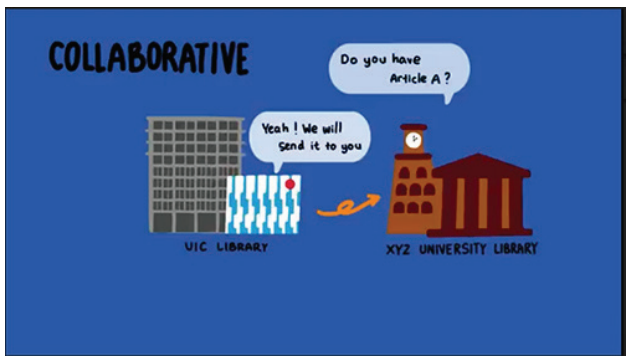

Screenshot of the ILL tutorial.
We posted the job ad in the beginning of spring semester 2020 and were delighted to receive several applicants. Relevant work experiences of applicants included recording music, making and editing videos for class assignments, tutoring, working as a campus housing resident advisor, retail customer service, IT helpdesk work, and administrative roles in student clubs. We also approached one student based on the promising work she completed in one of our Honors Seminar's courses to see if she wanted to interview. Her project for that class related to encouraging young girls to pursue careers in computer science and web design.

We interviewed five candidates for the two positions, ultimately choosing two: our former student (a computer science major) and an industrial design student who had collaborated on several team start-up projects and wowed us and design goals deliberately amorphous, hoping that this would free students to design something uniquely their own, which could have only resulted from their collaboration.

\section{Finding student interns}

Though this project could provide valuable resume experience, it was essential to us that students be paid for this work. Our first step was to write a job ad for undergraduate student workers focused on skills useful to this project. We advertised for two creative, self-directed library interns interested in investigating tutorial tools, outlining scenarios, and scripting and creating online tutorials. Job qualifications included an interest in exploring best practices of online learning and creativity with video, text, images, and audio narration. We stressed the collaborative nature of the positions. While we didn't expect to find students with tutorial- building experience, we hoped to work with students who had some sort of tutoring or teaching experience, who would be familiar with breaking down a difficult concept into smaller steps. We estimated the job would require two or three hours per week on a flexible schedule. with an explanatory video she made for chemistry class.

\section{Process}

The beginning stages of the students' work revolved around gathering information about library research and library tutorials in general. Students observed an information literacy sesexperience from library instruction. Although one of our students had attended a session as a first-year student herself, she found it beneficial to have a refresher. We talked about the sessions as a group, with the students contributing their thoughts on topics covered and not covered and what users might find most useful from a tutorial. We also learned about their own research experiences and processes and walked them through some of the library databases with which they were unfamiliar. The students read articles about library tutorials to learn about best practices in library tutorial design, and we asked them to find and view several library tutorials on their own. We then met and talked about what they liked and didn't like about the sion to become familiar with what most students 
tutorials, encouraging the students to give us their honest opinions, and discussed what they might want to emulate-or avoid—in designing their own tutorial.

The students found UCLA's design toolkit immensely helpful. They completed the Fundamentals in Learner-Centered Design minicourse, which involved reflecting on their own learning experiences, and introduced them to active learning, constructivism, critical pedagogy, and universal design. We spent some time discussing what made their previous learning experiences either positive or negative, and how they might keep this in mind when designing their tutorial. After thinking about a variety of potential topics, they decided to create their tutorial on constructing effective searches with keywords and Boolean operators.

Once they decided on their topic, they opted to use Adobe Premiere Pro video editing software, mainly because both of Screenshot of the research tutorial. them already had access to it, and we didn't have the budget to purchase new software. They used storyboarding to map the text and images and decided on animation to help teach the concepts. They both felt that animation was not only a good pedagogical tool, but also could help engage students and keep them interested in the video.

Shortly after we began meeting, our campus shut down due to the COVID-19 pandemic. While we struggled to figure out what the library was going to do, we put the project on hold so that our students could get used to online classes, and so we could adapt to online teaching and reference services. Once we realized we'd be working remotely for a prolonged period of time, we asked the students what they wanted to do. They were so invested and enthusiastic about the project that they wanted to keep meeting, but online rather than in person.

When the tutorial was partially finished, we asked for feedback from both students and other librarians. After making revisions such as deleting music and fixing some audio, the students continued working and meeting with us to report on their progress, ask questions, and get additional feedback.
After the success of the first tutorial, we invited the students to use their remaining work hours to embark on the design and development of a second tutorial. This time they chose the topic of interlibrary loan, one which was conceptually simpler, as they needed to complete the tutorial in a much shorter time frame.

\section{Outcomes}

By fusing their individual talents and creative vision in a collaborative learning and working environment, the two students created two highly original and complex animated tutorials that support the information literacy initiatives at our library. Rather than communicating research concepts from the point of view of a librarian or educator, these tutorials communicate a student's understanding of information literacy concepts to an audience of students. Furthermore, this communication is not only conceptual, but comes across in the narration, scripting, and visual design of the tutorials. ${ }^{4}$

Having a new tutorial during the pandemic which masterfully, clearly, and engagingly communicates these ideas to students - whether in synchronous or asynchronous settings - has been an invaluable fortification to our online instruction for a number of different programs, including, but not limited to, First-Year Writing, Communications, and Education. Although we have not conducted empirical research on the success of this particular tutorial in communicating information literacy concepts, we have anecdotally observed that it fulfills a need for demonstrating how to break down a topic into a series of keywords and how to enter those keywords into "the jaws of the search engine," as phrased in the tutorial.

\section{Conclusion}

This student-driven approach to creating online learning materials proved a success. Our student interns benefited from team-based learning and were proud of their finished tutorials. Through this model is based on collaboration and mentor- 
ship, we gained valuable insight into the student perspective on information literacy. We would like to thank Renee Romero, Doug Worsham, and Annie Pho for their engaging conference presentation and the WI+RE toolkit. We would not have embarked on this project without them planting the seed and laying the groundwork for collaborative, reflective, team-based learning and content generation.

\section{Notes}

1. Renee Romero, Doug Worsham and Annie Pho, "Better Together: Student-Led Collaborative Media Creation" (presentation, LOEX, Minneapolis, MN, May 10-11, 2019).
2. UCLA Library, "WI+RE: Writing Instruction + Research Education, https:// uclalibrary.github.io/research-tips/ (accessed May 3, 2021).

3. Annie Armstrong and Helen Georgas, "Using interactive technology to teach information literacy concepts to undergraduate students," Reference Services Review 34, no. 4 (2006): 491-97.

4. The tutorials have been embedded on numerous research and subject guides and web pages on our library's website, such as the First-Year Writing Program guide (https://researchguides.uic.edu/ intro) and the Interlibrary Loan webpage (https://library.uic.edu/help/article/1935/request-items ). $\boldsymbol{n}$

("Diversity in local and comparative contexts," continued from page 461)

Aboriginal research," in L. A. Brown (ed.), Research as resistance: Critical, Indigenous and anti-oppressive approaches (Canadian Scholars Press, 2005), 97-126.

7. Brian Arao and Kristi Clemens, "From safe spaces to brave spaces: A new way to frame dialogue around diversity and social justice," in L. Landreman (ed.), The art of effective facilitation: Reflections from social justice educators
(Sterling, Virginia: Stylus Publishing, 2013), 135-150, https://www.gvsu.edu/cms4/asset/843249C9-B1E5 -BD47-A25EDBC68363B726/from-safe-spaces -to-brave-spaces.pdf.'

8. Jamaican Historical Society, "Decolonizing Jamaican History: An Unfinished Project," JHS webcast series, 2020-21. z

\section{\# CHOICE WHITE PAPER
Implementing
and Managing Streaming Media Services in Academic Libraries* READ THE WHITE PAPER AT
CHOICE360.ORG/RESEARCH-PAPERS \\ *Underwritten by Infobase}

